International Drug Policy Consortium

A global network promoting objective and open debate on drug policy

IDPC response to the UNODC World Drug Report 2012

October 2012 


\section{IDPC response to the UNODC World Drug Report 2012}

October 2012

\section{Introduction}

26 June 2012 saw the launch of the United Nations Office on Drugs and Crime (UNODC)'s flagship publication, the World Drug Report. While it is now the norm to coordinate the launch with the International Day against Drug Abuse and Illicit Trafficking and hold simultaneous events in various national capitals, this year's primary launch arguably received a higher profile than in previous years. This was due to its inclusion within the opening section of the General Assembly's thematic debate, 'Drugs and Crime as a Threat to Development', in New York. Here, in front of the convened national delegations, the President of the General Assembly, Nassir Abdulaziz Al-Nasser, and the UN Secretary General, Ban Ki-moon, provided introductory remarks before the Executive Director of UNODC, Yury Fedotov, gave a more detailed account of the Report's contents.

This year's publication represents an impressive and wide-ranging set of data collated and analysed by UNODC and provides an overview of recent trends and the current situation in terms of production, trafficking, consumption and the consequences of illicit drug use for treatment, drug-related diseases and drug-related deaths. The World Drug Report 2012 is presented in a new slimmer and more accessible format - this year it is only 100 pages long, more than half the size of the 2011 publication - and is divided into two main chapters. Based upon data returned by governments up to 31 December 2011 (see Box 1), the first of these chapters looks at market trends. In what is essentially a return to the inclusion of a thematic chapter, the second offers a long-term perspective on the characteristics and evolution of the 'drug problem' and the main factors that shaped it.
Although the setting ensured that Mr Fedotov's comments in New York were framed very much within terms of crime and development, his principal message was that the Report's findings revealed stable but shifting global illicit drug markets. The Report suggests in headline terms that, with the exception of increased levels of opium production in Afghanistan, there has been no significant change in the 'global status quo' regarding the 'use, production and health consequences of illicit drugs' (p.1). As we shall see, this is a theme that chimes with the prioritisation of the market containment narrative within chapter two. Yet, the detailed information within the Report also signals significant changes, emerging complexities, regional variations and on-going flux in not only patterns of production and trafficking, but also in the illicit use of controlled drugs. For example, while cocaine production has declined in Colombia there appears to have been an increase in coca bush cultivation and coca production in both the Plurinational Republic of Bolivia and Peru. We are told that opium production might have declined in Mexico, but that it has gone up in Myanmar and the Lao People's Democratic Republic with, after plant disease within the country in 2010 , a substantial resurgence in Afghanistan. Data within the Report also demonstrate the apparent dynamism of drug trafficking organisations (DTOs) to deal with both naturally induced market disruptions and the efforts of law enforcement agencies. For example, the coastal states of West Africa have become increasingly affected by trafficking activities.

Further, as noted in previous Reports, and IDPC responses to them, prevalence patterns at a number of levels continue to shift. For instance, 
in the United States cocaine use remains in decline but data show that users are switching to other drugs, including methamphetamine and prescription medicines (see Box 2).

The use of new psychoactive substances (see Box 3 ) is also changing the shape and nature of consumer markets. Meanwhile the apparent decline in the US cocaine market has to some extent been offset by increases within Europe, and perhaps 'hidden populations' in other parts of the world. Indeed, despite comments at the launch about how the Report is helping us to understand a 'complete picture regarding the international drug problem', 'the uncertainly of the data once again remains a key theme running throughout the publication (see Box 1).

While this is the case, from its first pages the Report also adopts an overtly defensive position on the efficacy of the current international drug control system and the conventions upon which it is based. Within his preface, Mr Fedotov makes explicit reference to the 'need to move as one; if not', he warns, 'we risk going backwards, not forwards' ( $p$. iv). The phrasing is reminiscent of his opening speech at the $55^{\text {th }}$ Commission on Narcotic Drugs, at which he spoke of the importance of the 'Convention Songbook'. On that occasion he informed us that, "like any choir, we must sing in harmony. We cannot be out of tune. To ensure this, a commitment is required from us all to acknowledge the importance of the Convention songbook'. ${ }^{2}$ The Preface, and frequently the extended analysis contained in the Report proper, repeats that call. Such interventions leave us in no doubt that UNODC perceives the drug control system as being under threat of unravelling. In Mr Fedotov's terms, any questioning, such as that emanating from Bolivia and more recently - and although from a different perspective - Uruguay, that could lead to reform of the treaties would be going backwards, while going forward entails the reaffirmation of an unwavering commitment to them. The problem with this position, which is perhaps understandable for a man who leads the agency which is in many ways the public face of the drug control system, is that it is already apparent that we are not moving as one; that is, there are dissenting voices in the drug control debate, a discussion which is slowly but steadily becoming more open and diverse. Some UN member states clearly feel that the drug control conventions are no longer able to accommodate the solutions to their national dilemmas- at least as currently interpreted.

With these issues in mind, here we provide an overview of the data and topics presented in the Report and where appropriate, within the broader context of the current state of the UN drug control framework, offer a critical analysis of both.

\section{Box 1. Data, the on-going challenge}

Like previous recent reports, a key and reoccurring theme within this year's publication (in both the main text and the separate methodology section) is poor, outdated or non-existent data sets, particularly in relation to areas of increasing concern such as Africa and Asia. UNODC stress in the opening pages of the Report that 'Considerable challenges... remain in the reporting of trend data on illicit drug use, production and trafficking' (p.3). It continues to point to the fact that the 'Main challenges continue to be the availability and reporting of data on different aspects of illicit drug demand and supply in Member States. The lack of data is particularly acute in Africa and parts of Asia, where data on the prevalence of illicit drug use and trends remain vague at best. Other aspects such as process and purity of drugs, seizures and trafficking patterns and methodological difficulties in estimating in some regions and the illicit production of substances - particularly cannabis and ATS - make it difficult to analyse and 


\section{IdPC}

present a complete picture of the ever evolving illicit market' (all emphasis added). Faced with such a dilemma, UNODC is forced to adopt methods of extrapolation that may be misleading. For example, while a welcome attempt to move away from regional comparisons, estimating Indian ATS use via imputation from data from neighbouring states risks overlooking cultural differences and country specific circumstances. ${ }^{3}$ On this problem in general, UNODC perhaps rather optimistically concludes 'Most of the challenges can be overcome by sustained efforts in priority regions and countries to support and improve the collection of quality data on these different aspects of illicit drug use. It is only then that the ebb and flow of the world's illicit drug market can be measured' (p. 3).

Yet, that a constant feature of IDPC's response to the World Drug Report is a focus on the poor Annual Report Questionnaire (ARQ) response or completion rates suggests that more effort is still required within this crucial area. This year, for example, UNODC sent out the ARQ to 192 Member States as well as 15 territories. In response it received 91 replies to its questionnaire on 'The extent and patterns and trends in drug use' (ARQ Part III) and 94 replies on Part IV, 'Extent and patterns and trends in drug crop cultivation, manufacturing and trafficking'. This represents a drop from 2010 when UNODC distributed ARQs to 195 countries and 15 territories and received 107 replies on drug consumption and 106 replies on illicit supply. In 2011, the best response was from Member States in Europe where over 80 per cent of the countries responded, in Asia more than half ( 60 per cent) responded and in the Americas more than 40 per cent of countries filled in the ARQ. In the case of Africa, nearly 20 per cent of Member States, and in the Oceania region, only 2 out of 14 countries responded. As in previous years, the quality on Part IV is significantly better than for information on drug demand. Analysis of responses on Part IV revealed that 86 per cent were 'substantially' completed compared to 61 per cent of Part III. ${ }^{4}$ Although conscious of the manifold problems associated with data capture on certain drug groups in some, particularly developing, countries, it is only when ARQ returns improve that UNODC will be able to reduce the currently inherent levels of uncertainty within its annual publication.

\section{The extent and changing patterns of illicit drug use}

The Report takes every opportunity to highlight that the extent of illicit drug use has remained stable in the 5 years up to and including 2010. Continuing with the UNODC's now well established practice of preferring ranges over point figures, it is estimated that between 3.4 per cent and 6.6 per cent of the global adult population (defined as persons aged 15-64) had illicitly used a controlled substance at least once in the previous year. This equates to an estimated global figure in 2010 of between 153 million and 300 million users. Within this population, it is estimated that around 12 per cent, between 15.5 million and 38.6 million, are 'problem drug users', including those 'with drug dependence and drug-use disorders'; a group that 'remain a particular concern' (p. 7) (see Box 2). As in previous years, such an approach includes the unavoidable admission that the majority of people who use controlled drugs illicitly are in fact non-problematic. 


\section{Box 2. Non-medical use of prescription pharmaceuticals}

Although global figures for the non-medical use of prescription drugs other than opioids and amphetamines are not available, the use of drugs including tranquilisers and sedatives (such as the benzodiazepine family, diazepam, flunitrazepam or temazepam, methaquolone and barbiturates) is reportedly a growing health problem, with prevalence rates higher than for numerous controlled substances in many countries (p. 3). In the USA, for example, lifetime, annual and monthly prevalence of non-medical use of psychotherapeutics (mostly pain relievers) among those aged 12 years and over was reported as 20.4 per cent, 6.3 per cent and 2.7 per cent respectively for 2010. This is higher than for any drug other than cannabis. There is also a big rise in the use of pharmaceuticals for non-medical purposes in Australia. Additionally, while drug use among men greatly exceeds that among women, the non-medical use of tranquilisers and sedatives among women is, where data are available, 'a notable exception to the rule' (p.3). For instance, a 2009 survey in Afghanistan by UNODC and the Ministry of Counter Narcotics found that more than 10 per cent of people who use drugs had used tranquilisers without medical prescription in their lives, that women who use drugs were twice as likely to have used them than men, and that most of the women were daily users. Similar pictures are provided for countries in South and central America and Europe (p. 13).

Also of note are the findings presented showing that in general, in the normal lifecycle of drug use, there is a sharp decline in lifetime, annual and last month prevalence of non-medical pharmaceutical drug use with increasing age. Data on non-medical use of tranquilisers and sedatives in European countries suggest, however, that the rate of attrition of use is much lower especially among women (p. 14). There is also evidence that these substances are being used increasingly in combination with traditional controlled substances, in poly-drug use 'designed to either enhance or counterbalance their effects' (p.3).

With this in mind, in global terms the two most widely used drugs remain cannabis and amphetamine-type stimulants (ATS). The global annual prevalence of cannabis ranges from 2.6 per cent to 5.0 per cent; between an estimated 119 million and 224 million adult users. The Report notes that, while there may be shifts in use between cannabis resin and cannabis herb and that there is evidence of the increasing popularity of synthetic marijuana among young people in some regions, the general annual prevalence of cannabis use remains stable. The highest prevalence for cannabis was reported in Oceania (principally Australia and New Zealand) with a range of 9.1 per cent to 14.6 per cent of the adult population. This was followed by North America (10.8 per cent), West and Central Europe ( 7 per cent) and West and Central Africa
(5.2 per cent to 13.5 per cent). It is important to note that although the estimated prevalence of cannabis use in Asia (1.0 per cent to 3.4 per cent) remains lower than the global average, the size of the region's population make the absolute numbers (26 million to 92 million) the highest worldwide. Further, of great significance is the news that in 2010 experts in many countries in West and Central Africa, South Africa, South Asia and Central Asia noted perceived increases in cannabis use - while UNODC note that 'data on illicit drug use in Africa is limited' (p. 11) cannabis is reckoned to be the most commonly used drug in the region.

As the second most widely used controlled drug globally, data for ATS, excluding 'ecstasy', reveal prevalence levels of 0.3 per cent to 1.2 per cent 


\section{IdPC}

of the adult population in 2010 (14.3 million to 52.5 million users). Increasing reports of methamphetamine seizures in South West Asia, Central Asia and Transcaucasia, as well reports on illicit substance use in some other areas, are leading to speculation that use of this variant may be increasing in those sub-regions. Again, mindful of the limitations of data for the region, the use of ATS is also seen to be increasing within Africa.

The figures for ATS do not include 'ecstasy' group substances (mainly methylenedioxymethamphetamine (MDMA) and its analogues), which are estimated to be used by 0.2 per cent to 0.6 per cent of the global population aged 15-64 (10.5 million to 28 million users) - levels that are comparable to the prevalence of cocaine use. It should be noted that higher rates, especially among young people, were reported in Oceania, North America, and West and Central Europe (p. 12). Indeed, while 'ecstasy' use had previously been declining, we are told that it 'appears that it started to increase in 2010' (p. 10). While overall trends in Europe have remained stable, 'reports indicate an increase in the purity of 'ecstasy' available in Europe and a possible resurgence in its use' especially among what are termed 'club goers' (p. 12). In the USA, there are also reports of a 'resurgence' of 'ecstasy' use, particularly among high school children (p. 12). There is, however, a declining trend in Australia.

The available data in the Report demonstrate that the global annual prevalence of both cocaine and opiate use has remained stable overall, with ranges from 0.3 per cent to 0.4 per cent, and 0.3 per cent to 0.5 per cent respectively, for the adult population.

\section{Box 3. The challenge of new psychoactive substances}

As in recent years, the World Drug Report 2012, highlights at various points that new chemically engineered psychotropic substances designed to remain outside international control are increasingly being used and identified. In numerous countries, particularly within Europe, North America and Oceania (principally countries with good data capture systems), reported use of these substances was an emerging and increasingly problematic trend in 2010. In Europe, for example, UNODC stresses that while there may have been a stabilisation or decline in traditional drug use, the 'rapid emergence of new synthetic drugs and increasing interplay between legal 'highs' and the illicit market pose a major challenge in the region' (p. 22).

Most notable among these substances were methcathinone analogue 4-methyl-methcathinone (mephedrone), and methylenedioxypyrovalerone (MDPV), often labelled as bath salts or plant food and used as substitutes for stimulants such as cocaine or 'ecstasy'. The Report also shows that several synthetic cannabinoids that emulate the effect of cannabis but contain uncontrolled products have been detected since 2008 in herbal smoking blends.

Other uncontrolled synthetic substances also being used to substitute or mimic the effects of controlled drugs have been reported. These include indanes, benzodifuranyls, narcotic analgesics (such as codeine converted into desomorphine in the Russian Federation), synthetic cocaine derivatives, Salvia divinorum (dried leaves of a plant native to Mexico with hallucinogenic effects reported in Canada), ketamine (commonly reported in South East Asia) and phencyclidine derivatives (p. 14). 
'Kratom', a product derived from Mitragyna speciosa Korth, a tree found in South East Asia, has long been used to treat opioid withdrawal within the region (p.15). It has dose-dependent effects, with a stimulation effect at low doses and opioid effects at high. Reflecting the increasingly global nature of both the illicit market and that for new synthetic substances, while kratom use is most prevalent in Malaysia, Myanmar and Southern Thailand, the EMCDDA show that it is also widely offered on the internet.

Similarly, as with the traditional illicit market, DTOs continue to adapt their manufacturing strategies in order to avoid detection, 'and such changes in the illicit manufacturing process of synthetic substances present new challenges to drug control authorities worldwide' (p. 3).

With the estimated annual prevalence in 2010 ranging from 0.6 per cent to 0.8 per cent of the population aged 15-64, the use of opioids $^{5}$ (mainly heroin, morphine and nonmedical use of prescription opioids) is stable in the main markets, although North America, Oceania and East and South East Europe have higher than the average prevalence of opioid users. Of the estimated 24.6 million to 36 million people who use opioid, it is reckoned that 13 million to 21 million use opiates, especially heroin. The latest data suggest that heroin use is declining or stable in Europe. However, countering such a picture of stability in Europe and in other main markets, we are told that 'Experts in Asian and African countries perceive that heroin use has increased in their regions' (p.7). Furthermore, and once again reflecting the dynamic nature of the illicit market, the Report reveals that the use of synthetic opioids appears to be on the increase in some European countries. There is evidence, for example, that in Estonia and Finland fentanyl and buprenorphine have displaced the use of heroin (p. 9). In some parts of the Russian Federation, a recent heroin shortage (see below) has led many users to use desomorphine (also known as 'krokodil'), acetylated opium or fentanyl as substitutes.

Similarly, while global cocaine use overall appears to remain stable at 13.2 million to 19.5 million users, changes are taking place in the patterns of use. There has, for example, been a substantial decrease in prevalence in North America and some countries in South America. The USA in particular has experienced a decrease in prevalence from 3.0 per cent in 2006 to 2.2 per cent of the adult population in 2010. According to the Report, this 'can be linked to a decline of 47 per cent in cocaine manufacture in Colombia' with the 'turf wars' between DTOs and law enforcement agencies in Mexico perhaps also being a factor (p. 37). As IDPC has noted in the past, explaining market shifts is a complex issue and accurate attribution is extremely difficult, if not impossible, to establish. Consequently, while these factors may indeed have impacted upon prevalence figures, other variables, such as market maturation, must not be overlooked. The Report indicates that Europe has not experienced a decline in supply on same magnitude as the USA, although prevalence has started to stabilise in some countries and decline in others. Despite such changes in patterns of cocaine use, the highest prevalence remained in North America, West and Central Europe and Oceania. There are also indications of increases in cocaine use in Oceania, Asia, Africa and some countries in South America, notably Brazil. 'Anecdotal' information on increasing trafficking through African coastal countries in combination with the limited available data on use, points towards increases in this region. 


\section{Idpc}

\section{Box 4. Drug use and health consequences}

While UNODC highlights the stability of prevalence levels, it also gives some, but arguably insufficient, prominence to the continuing negative health consequences of drug use. While this also relates to the non-medical use of prescription drugs (See Box 2) this is particularly so in relation to the 10-13 per cent of the drug using population defined as problem drug users, especially those who inject. According to the soon to be disbanded Reference Group to the United Nations on HIV and Injecting Drug Use, a move that does not bode well for the collection and analysis of data in this area, figures from 2007 reveal that of the estimated 16 million injecting drug users, about 3 million are living with HIV. With the exception of sub-Saharan Africa, injecting drug use accounted for approximately one third of all new HIV infected globally in 2010. The prevalence of hepatitis $C$ and $B$ were estimated at 46.7 per cent and 14.6 per cent respectively; a situation that continues to add to the global of disease.

IDPC has noted in previous briefs, ${ }^{6}$ and the Report acknowledges this year, that there remain complications with the calculation of drug related deaths. However, we are told that that 'approximately 1 in every 100 deaths among adults is attributed to drug use' (p.1). More specifically, UNODC estimates that illicit drug use resulted in between 99,000 and 253,000 deaths globally, with drug-related deaths accounting for between 0.5 per cent and 1.3 per cent of all-cause mortality among those aged 15-64 (p. 7) - figures that are in line with those produced by WHO. Demonstrating another example of UNODC good practice, the differences in figures from last year, and wide ranges presented for a region like Asia, reflect caution about uncertainty where no mortality data are available ( $\mathrm{p} .17)$. It is also noteworthy that 'The number of deaths attributed to the non-medical use of prescription painkillers in the United States has risen steadily to a level that now exceeds the combined number due to heroin use $(5,110$ deaths) and cocaine use (3,000 deaths) (p. 19).

Meanwhile, patterns of drug related deaths also appear to be changing in countries to the south. Although drug related deaths in South America are below the global average, we are told 'Throughout the region cocaine continues to be ranked the most lethal drug'. Significantly, however, the Report goes on to say that 'it appears that in some countries in Central American and the Caribbean, the higher homicide rates are, in part, linked to organized crime and conflicts related to cocaine trafficking flows and cocaine markets' (p. 20). Surprisingly, despite some discussion in the publication of law enforcement activities in Mexico, this is the only reference to the extreme levels of related violence within that nation.

\section{Trends in illicit drug production and trafficking}

In headline terms, UNODC estimates that the production of opium increased from 4,700 tons in 2010 to 7,000 tons in 2011. Afghanistan's potential opium production resurged to 5,800 tons in 2011 , following a brief fall to just 3,600 tons in 2010 due to widespread disease of the opium poppy within the country. Significant increases were also reported in the other main producing states of Myanmar and the Lao People's Democratic Republic. Preliminary estimates for Mexico suggest that production has decreased, although at the time of publication 2011 data for the Americas (Mexico, Colombia and Guatemala) were not available (p. 26). 
In terms of breaking down the processing of the 7,000 tons, it is estimated that 3,400 were consumed or trafficked as raw opium, with the remainder converted to heroin. This results in an estimated figure of 467 tons of potential heroin manufacture in 2011, up from an estimated 384 tons in 2010. UNODC also estimate that, compared with previous years, a lower percentage of Afghan opium was processed into heroin in 2011. While suggesting an interesting trend, its veracity is left in some doubt due to a lack of clarity concerning the methodology behind these data.

While we need to be aware of such limitations, we are informed that the total global area under poppy cultivation increased between 2010 and 2011; from 191,000 hectares to 207,000 hectares. Once again, we are informed that 'Afghanistan remains the main country cultivating opium poppy, accounting for approximately 63 per cent of global opium cultivation' ( $p$. 27) with poppy production returning to 2009 levels. The Lao People's Democratic Republic and Myanmar were responsible for 20 per cent of the global total, with countries in Central and South America making up almost 7 per cent of the area under poppy cultivation. Significantly, again if the data is accurate, the Report also notes the existence of 'smaller areas under illicit opium poppy cultivation in many other countries and regions,' including India and Guatemala (p. 27). Although the Report notes that UNODC draws on additional sources of data $^{7}$, it would be interesting to discover how it reached this conclusion with regard to these specific countries, since it does not receive survey data from either of them.

As noted above, the Report shows that, despite the shortfall in opium production in 2010 , the consumption of opiates remained stable, and even declined in some places (such as the USA) as users shifted to synthetic substitutes. Indeed, average wholesale and retail markets in the most regularly monitored markets for opiates (Western and Central Europe and the Americas) have shown little change since
2009. This, however, does not seem reflect the situation seen in major opium producing countries like Afghanistan and Myanmar, where despite an increase in opium production, farmgate prices continued to rise. The Report notes that 'The latter implies that, despite the recent recovery of opium production, the demand for opium is continuing to increase' (emphasis added). To this we might also add that, although not specifically mentioned in this year's Report, UNODC's previous assessment of an inventory, or stockpile, of opium in Afghanistan is off the mark. ${ }^{8}$ While ignoring this point, the authors of the Report then pose the following set of questions:

- What exactly are the reasons for this apparent increase?

- Is the 2010 crop failure in Afghanistan leading to some kind of shift in the markets at source?

- And if so, how will this impact on the major illicit market for opiates further down the line? (p. 26).

UNODC admits that it is difficult to identify specific explanations. It does, however, offer a number of suggestions. Core amongst these is the unavoidable idea that there may be an underestimation in global heroin consumption, especially, as suggested above, in emerging and currently hidden markets in Asia and Africa ( $p$. 30-34). In reference to current control efforts, the Report also suggests that 'increasing prices at source may not reflect higher demand but rather an increased risk in cultivation and trafficking resulting from the intensification of law enforcement activities' or an expansion in the market for raw opium (i.e. that not processed into heroin), which could feed increased opium consumption and, perhaps, a parallel illicit market for opiates such as morphine' (p. 30). Although we are not provided with any evidence for this contention, we are also informed that high prices at source could also be explained by speculation in the local market (p.1 \& 30). Within the context of the picture painted, all these scenarios offer plausible explanations. 
However, the analysis of data sets other than the 'others' obliquely referred to in the separate (and dense) methodology section of the publication may offer alternatives ${ }^{9}$

The Report itself admits that it is still too early to know the exact impact of the 2010 opium crop failure in Afghanistan on major illicit markets for opiates. There was a general decrease in seizures in 2010 in most countries supplied by Afghan opiates and a heroin shortage observed in some European countries in 201011. Consequently, it is noted that 'While these changes may not reflect a uniform and rapid response..., it is reasonable to assume that they reflect a rapid reaction in the markets of the countries closer to Afghanistan or those supplied through direct routes leading from Afghanistan' (p. 30). As noted earlier, there is evidence that the shortages resulted in some substance displacement and 'encouraged' users in some countries to replace heroin with other substances such as desomorphine, acetylated opium (known as 'kompot') and synthetic opioids such as fentanyl and buprenorphine.

UNODC notes that perceived heroin shortages in UK may have been down to law enforcement efforts in Turkey, but also suggests that since it appears that heroin in the country comes more directly from South West Asia, the decline in Afghan production caused by disease was the more likely cause. The Report also notes that 'Other measures or circumstances may have made the shortage more severe in some countries' (p. 32). The implicit, and not unreasonable, message running throughout the discussion of the illicit opiate market is that 'we cannot explain the current but obviously shifting situation'. While this is the case, UNODC admits that DTOs are clearly 'adept' at responding to market changes, especially law enforcement activities, and that this reality may mean that the impact of counter drug strategies may be short-lived and act to diversify rather than eliminate trafficking routes (pp. 32-33). In this respect, it is reported that large quantities of heroin continue to be trafficked along the main Balkan route (Afghanistan to Western and Central Europe via South-Eastern Europe). Yet declining seizures were reported in most of the countries in these regions in 2010 (against a backdrop of slightly increased global seizures). However, reinforcing the idea that Africa and Asia are increasing areas of concern, the Report notes that 'coastal markets of Africa are reporting increasing seizures, as are markets in South-East Asia..'. Reflecting the on-going uncertainly characterising the current state of the opiate market, it continues, 'Whether this implies that traffickers are seeking alternative routes or that heroin use is on the increase in those places, the lack of available data makes it impossible to draw definitive conclusions. But, one thing is clear: the opiate market continues to be extremely flexible and adaptable' (p. 2).

As with opiates, we are informed that 'The general stability of global cocaine use ... masks different trends in different regions and different countries' (p.2). Furthermore, despite a decline in production there has been no apparent fall in global cocaine consumption. Available data on cultivation, yield and trafficking indicate that there has been an overall decline in the global manufacture of cocaine in the five-year period 2006-2010 (p.2 \& p. 35). That said, the Report attributes this to a decline in cocaine manufacture in Colombia between 2005 and 2010, although there has been a sizable shift in the market as coca bush cultivation and coca production increased in the same period in Plurinational State of Bolivia and Peru (p. 2 \& p. 35 ). In 2010 , Bolivia was the site of 31,000 hectares of coca bush cultivation, with Colombia (adjusted to include small fields) double that and Peru close behind at 61,000 hectares ( $p$. 35). However, since the publication of the World Drug Report 2012, data from the 2011 national coca monitoring survey presented by UNODC and the Government of Bolivia revealed a drop in cultivation in that country to 27,200 hectares. ${ }^{10}$ It will be interesting to see how this affects the cocaine market. Indeed, it is significant that, despite such a fall, the White House determined Bolivia had 'failed demonstrably 
during the previous 12 months to adhere to [its] obligations under international narcotics agreements' and put forward the argument that Bolivia's potential cocaine production, the result of complex extrapolations largely ignored in this year's Report, had increased to exceed that of Colombia. ${ }^{11}$ Accompanied by opaque to nonexistent methodology, this is an obvious attempt to cast Bolivia as a threat to the international drug control system as La Paz continues in its quest to adjust its position on the traditional use of the coca leaf within the 1961 Single Convention on Narcotic Drugs. ${ }^{12}$

While serious questions exist as to how US authorities calculated the potential cocaine production figures released in September 2012, as is normally the case, the figures on coca production within the World Drug Report also raise issues concerning the differences between data sets and consequently issues of comparability and certainty. ${ }^{13}$ Conscious of the issue, the Report goes to some length to point out that 'numerous efforts have been made by UNODC and the Bolivian, Colombian and Peruvian Governments to ensure the comparability of the estimates of their respective areas under coca bush monitoring' (p. 40). All the approaches are scientifically based and reliant on remote sensing. However, differences in the size of monitored areas, the concepts used for the area under coca bush cultivation, climatic conditions, the availability of secondary information and security risks impeding access to growing areas have led the systems to use different implementation modalities, technologies and data sources (pp. 40-1). Data capture in Colombia is further complicated as high levels of eradication force coca growers into different harvesting patterns and to relocate geographically.

The Report also shows that, while the US market continued to be supplied almost exclusively from cocaine produced in Colombia, from 2006 there was a shift in the European markets, which compensated, at least partially, for the shortage of Colombian cocaine with that produced in
Bolivia and Peru (p. 39). On this point, UNODC admits that 'more investigation is necessary' (p. 39). Moreover, and again reflecting the dynamism of DTOs, the Report notes that 'The decline in seizures in Europe, despite the apparent stability of the region's cocaine supply, implies that a change in trafficking modes is occurring as traffickers may be making increasing use of containers' (p.2). In the USA, the decline in the availability of cocaine has been reflected in rising prices since 2007 . However, in Europe no dramatic changes in prices have been observed since 2007. Overall, 'they remained at the same level in dollar terms between 2007 and 2010 and even decreased in some countries' (p. 2).

Interestinglyinterms of shifting marketstructures, another factor influencing the availability of, and demand for, cocaine in different regions is the emergence of 'new, albeit small, cocaine markets in, for example, Eastern Europe and South-East Asia'. Reflecting a continuing trend, UNODC notes that 'There is also some evidence that cocaine trafficking through West Africa may have had a spill-over effect on countries in that sub-region, with cocaine emerging as a drug of major concern, along with heroin' (p. 2). Furthermore, increases in Bolivia and Peru may be driven by demand for cocaine in different regions outside main markets of North America, Western and Central Europe and South America. Reinforcing the continuing uncertainty around emerging geographical areas of concern, the Report advises that 'Since no recent studies on prevalence are available for these emerging markets, the upward trend in cocaine seizures in such markets could highlight an emerging problem that is not yet visible in demand data' (p. 40). There is also limited information on other markets, including potentially significant states with growing urban centres, and hence potentially large numbers of cocaine users, like India and China.

Shifting patterns and considerable uncertainly also characterise the Report's description and analysis of the production and trafficking of ATS. 
However, unlike cocaine, global ATS production is increasing. The illicit manufacture of ATS (mainly methamphetamine, amphetamine and 'ecstasy') 'is difficult to measure because it is widespread and often on a small scale' ( $p$ 2). Although, the use and global seizures of ATS remained largely stable, 2010 was marked by an increase in methamphetamine seizures to more than double the amount of 2008. This was partly due to seizures increasing in Central America (principally Mexico) and East and South East Asia. Reflecting prevalence, the Report states that, 'For the first time since 2006, global methamphetamine seizures surpassed global amphetamine seizures, which fell by 42 per cent (to 19.4 tons) mainly as a result of a decrease in seizures in the Near and Middle East and South-West Asia' (p. 51). Additionally, despite significant rises in the dismantling of clandestine amphetamine laboratories, seizures of the drug in Europe continued a downward trend, reaching their lowest levels since 2002 (5.4 tons). Seizures of 'ecstasy' in Europe, doubling from $595 \mathrm{~kg}$ in 2009 to 1.3 tons in 2010 , provide further evidence of a recovery of the market for the drug.

The Report also presents evidence to suggest that criminal organisations are increasingly involved with the smuggling of ATS, especially methamphetamine, and exploit West Africa in a similar way to cocaine traffickers. For example, seizures of methamphetamine from West Africa being smuggled into East Asian countries, mainly Japan and the Republic of Korea, started to increase in 2008. Increasing annual legitimate requirements for precursor chemicals of ATS (ephedrine and pseudoephedrine) in the Near and Middle East also suggest that some diversion into illicit markets is occurring. As with involvement in other drug markets, the Report highlights that DTOs continue to adapt manufacturing strategies in relation to ATS and present 'a myriad of new challenges to drug control authorities worldwide' (p. 51 \& p.56).

In terms of cannabis, production of the drug is stated to be a 'truly global phenomenon' ( $p$.
43). Seizure and eradication data suggest that the production of cannabis herb in particular is 'increasingly widespread' (p. 2), but the often localised, small-scale nature of cannabis cultivation and production make it difficult to assess. In fact, new data on large-scale global production of cannabis resin are only available for Afghanistan. The Report makes it clear, however, that there are differences in importance of cannabis herb and cannabis resin between regions. The more protracted mechanism of processing the cannabis plant into resin is confined to a relatively limited number of countries in North Africa, the Near and Middle East and South West Asia. In the rest of the world, including the USA where production continues to be high (especially indoor cultivation), herb forms of the drug are dominant. As is the case for other drugs, figures for Africa are especially hard to come by, but seizure data suggest that cannabis herb is also dominant across the continent except for North Africa (p. 43). The production of resin is 'assumed' to be small in Europe, the world's biggest market for resin (with North Africa and especially Morocco) long being Europe's main supplier. That said, the market may be restructuring as Afghanistan's role in resin production (and maybe that of India) increases. Interestingly, despite the frequent focus on the illicit poppy crop, cannabis is actually Afghanistan's most lucrative cash crop. ${ }^{14}$

While this is the case, the proliferation of indoor cannabis sites and 'differing trends in prices and seizures of cannabis herb and resin' indicate that there may be a shift in the European cannabis market, with most European Union member states reporting the cultivation of herb to be a 'phenomenon that appears to be on the increase' (p. 47). The Report claims that, while usually small scale, indoor cultivation may include major operations run by criminal groups choosing to supply local markets and reduce the risks of trafficking). Recent law enforcement activities in the Netherlands (the main producer of the herb within Europe) have apparently displaced production to Central, 
East and Northern Europe, while UNODC also concedes the increasingly widespread existence of businesses specialising in paraphernalia for growing cannabis (p. 48).

While again avoiding the hysteria of earlier Reports, ${ }^{15}$ UNODC again addresses the issue of cannabis potency: proposing that the '...rise in indoor cultivation of cannabis is often related to an increase in cannabis potency, which is reflected in the data only to a limited extent' (p. 3 $\& 49$, emphasis added). In a similarly measured and welcome manner, we are informed that 'Such increases in potency may explain, in part at least, the increase in treatment demand among cannabis users, though this may also be related to the cumulative effects of prolonged use.... It should be noted here that increased treatment demand for cannabis may also be a result of criminal justice approaches that favour non-punitive diversion. Interestingly, the Report also notes that the reported increase in domestic indoor cannabis cultivation cannot be easily linked to an increase in prevalence. Data for Europe indicate use has increased in a small number of countries, (including Sweden), but stabilised or decreased in others. The Report also states, 'It is not clear whether there have been changes in the amount consumed or if imported cannabis is being replaced by locally produced cannabis. Furthermore, other factors such as the decline in tobacco smoking among young people, changes in lifestyle and fashion or replacement by other drugs, may have influenced cannabis use' (p. 49).

\section{UNODC's cultural narrative of drug use: The return of the 'containment' thesis}

Chapter two of this year's Report is entitled 'The contemporary drug problem: Characteristics, patterns and driving factors', and makes an attempt to situate the illicit use of drugs in a historical and cultural context. IDPC has criticised previous Reports for concentrating solely on quantifying the 'world drug problem', ${ }^{16}$ while disregarding the cultural meanings that drug use has both for its participants and for social and political authorities. ${ }^{17}$ Chapter two therefore represents a positive development, and makes for an interesting read. However, UNODC's overarching commitment to the present drug control regime led it to interpret the historical and cultural context of drug markets is in a way that tends to celebrate rather than attempt a balanced and realistic assessment of the existing regime. UNODC's established theme of containment (the restriction of illicit drug use to a relatively small section of the population approximately 5 per cent) remains prominent in this year's Report. By contrast, the unintended consequences of the drug control system, which were acknowledged and elaborated upon by a previous Executive Director, ${ }^{18}$ are mentioned but strongly downplayed.

\section{Outline of data presented in Chapter Two of the Report: 'The Contemporary Drug Problem: Characteristics, Patterns and Driving Factors'}

As indicated by its title, the chapter is organised into three main sections. Section A deals with the 'fundamental characteristics of the contemporary drug problem' (p.59) and covers the geographical spread of contemporary drug use, which as noted above is perceived to be stabilising in developed economies and expanding in developing ones; the growth and globalisation of the illicit drug market, and its impact upon society and state, measured in terms of health, productivity and so on. Section B examines the ways in which the characteristics of 'the drug problem' have shifted over time, setting out to map the shifts in the major drug markets. Section $C$ attempts to explore the driving factors that shape the contemporary problem. These sections continually overlap, and the following analysis traces this overlapping, rather than pursuing a strictly sequential outline. Finally, these three sections are supplemented by section D, 'Conclusion'- which, however, rather than drawing conclusions as such, summarises the materials elaborated in the Chapter's previous sections. 
While remarking that drugs have been 'consumed throughout history, in different forms' (p.59), the authors state that the present configuration has emerged over the past half century, and is characterised by 'a concentration of illicit drug use among youth, notably young males living in urban settings, and an expanding number of psychoactive substances...' (p.59). The chapter 'explains how it has been shaped by fundamental and enduring factors that define its nature, as well as by shorter-term development that have contributed to modifying its patterns over time' (p.59).

In its discussion of the 'main dimensions' of the problem, section A states that, against a backdrop of a global population of some 7 billion people, about 230 million used a controlled drug illicitly at least once last year. The figure represents approximately 1 in 20 people aged 16-24. In the same age range, some 1 in 40 have used drugs in the past month, and 1 in 160 'in a manner that exposes them to very severe health problems' (p.59). The authors locate the concentration of drug usage in the youth population, and in young men rather than young women. The chapter also seeks to show that when prevalence rates of licit and controlled drugs are compared, it is evident that 'the introduction of international controls has contributed to maintaining lower consumption rates for illicit drugs' (p.61).

Taking as its object the last 50 years, the chapter describes a set of usage trends for the mostly widely consumed drugs. In the case of cannabis - by far the most widely used - the large US market saw rising consumption in the 1960s and 1970s followed by 'steep declines' in the 1980s, and then another period of increase in the 1990s. Since the year 2000, the overall trend has been stable. The Report claims that, 'past month prevalence of cannabis use among persons aged 12-34 as well as annual prevalence among persons aged 12 and over in the United States, is...some 50 per cent lower than the 1979 peak' (p.73). While patterns of cannabis use elsewhere in the world differed, the overall picture is one of stabilisation and decline following an earlier peak. The trends for other drugs tend to be similar, though recent displacements of geography and substance, which render the matter more differentiated and complex, are also reported. The point UNODC makes is that the general trend is one of stabilisation.

\section{The Report's use of data to support the UNODC containment thesis}

How are these data sets situated in terms of the Report's overall explanatory framework? Essentially, they are deployed in support of UNODC's containment thesis - the argument that, while drug use has not been entirely erased to realise the utopia of a 'drug free world', it has nevertheless been restricted to a minority population, especially in terms of the more problematic forms of drug use. It is a contentious argument, particularly given the difficulty of examining the world without the present drug control regime in order to isolate and compare its effects. Yet the Report finds further support for its 'containment' claim by informing the reader that tobacco and alcohol use, the two major licit intoxicants, are much more widely used than their controlled counterparts, at respectively 10 times and 8 times the prevalence rate. It claims that this constitutes evidence of the restrictive effect of existing efforts at drug control.

However, when more closely analysed, these figures can easily be interpreted to mean something very different, particularly when their use is situated in cultural terms rather than just viewed in the abstract. For instance, if we take Europe as an example, the use of alcohol in the form of wines and beers goes back many centuries and is thoroughly embedded in social and cultural life. The cultural historian Wolfgang Schivelbusch notes that, 'Prior to the introduction of the potato, beer was second only to bread as the main source of nourishment for most central and north Europeans'. ${ }^{19}$ Beer was understood as a food at this time in European history, and most working people would consume a beer soup for 
breakfast. Additionally, alcohol was used in bouts of extreme intoxication, and was drunk in great quantities on a host of ceremonial occasions. The movement toward more moderate modes of alcohol use involved not only ideological changes regarding the value of abstinence (such as those stemming from Puritanism and early capitalism), but also the advent of new drinks containing new psychoactive substances that could replace alcohol as devices that punctuated the working day: tea, coffee and chocolate being foremost among them. The drinking patterns evident in contemporary Europe emerged from the slow sifting of substances through social life into a set of embedded social and cultural norms. It is primarily these that regulate their use, rather than laws devised for the purpose. ${ }^{20}$ Attempts to prohibit the non-medical or recreational uses of alcohol in European and post-European societies such as the USA have not been successful. Indeed, a plausible argument can be made that alcohol is legal in 'Western' societies because it is so culturally embedded that attempts to regulate it along the lines of the drug control conventions- permitting 'scientific and medical' uses only would be massively resisted - and ultimately circumvented - as they were in the USA in the 1920s. ${ }^{21}$ Illicit drugs such as heroin and cocaine, on the contrary, were relatively new to the early twentieth century legislators who instituted the drug control regime. Contrary to the UNODC claim, this implies that alcohol is not more prevalent because it is legal, but legal because it is more prevalent.

\section{A problematic interpretation of the historical and cultural context of drug markets}

In addition to outlining what it believes to be the shape of the contemporary drug problem, the Report maps the contours of the state's role in regulating it. In this context, the text reiterates a second, now familiar, argument that drug problems across the nineteenth and early twentieth century world (opium addiction in China, hashish-linked insanity in Egypt) led to the construction of the international drug control regime whose primary focus has been on public health. IDPC has elsewhere critiqued this argument on historical grounds; in addition to public health imperatives, those of political and economic power were highly important factors, along with discourses of the racial superiority of the West. ${ }^{22}$

In a further elaboration of its analysis which takes us squarely onto the territory of cultural politics, the chapter goes on to trace 'the unfolding of today's drug problem in changing societies' (p.63). It argues that the 'expansion of today's illicit drug problem started with youth in North America in the 1960s, spread to Western Europe and, eventually, to the rest of the world'(p.63). The drug use of the 1960s was, the authors suggest, an element in youth culture and the counter-cultural movement which sought to reform Western societies. According to the authors: 'After the end of the war in Viet Nam and the social reforms of the 1970s in many countries, this broad youth protest movement largely faded away and with it the "ideological" basis for illicit drug use' (p.63). ${ }^{23}$ The notion that the changes of the 1960s resulted from a 'youth protest movement' that faded away at the end of the 1960s is somewhat simplistic. The ideas, attitudes and social changes that marked the decade were not without historical precedent, and did not disappear; indeed, many of them were embraced by a libertarian popular culture in which drug use continues to be celebrated. While UNODC notes the continuing linkages of drugs with various forms of youth culture, this section represents the agency's closest engagement of its drugs narrative with a historiographic narrative of twentieth century cultural change.

Despite noting that cannabis was linked to 'the jazz era of the 1920s' (p.63), the chapter tends toward a rather limited notion of the historical embedding of drug use in modern social and cultural life. It is correct to note that the cannabis use of the 1960s reached far larger sections of the population than its 1920 s forerunner, but, with its focus overwhelmingly on drug 


\section{IdPC}

as an issue of governance, UNODC fails to demonstrate an awareness of the long historical relationship between drugs and modernity, and the integral part these substances have played in the development of the modern world. David Courtwright has termed the impact of drugs on modern life 'the psychoactive revolution', ${ }^{24}$ and this is no exaggeration. This radical set of changes had its roots in the intercontinental explorations of the renaissance, the commerce of the spice trade and search for new routes to transport these luxurious items to the West. The beginnings of globalisation lay here, and a key part of the process was the confluence of the world's drugs - an on-going movement toward increasing psychoactive availability, variety and potency that was accelerated by the new science of pharmacology, which teased out ever more powerful alkaloids from the original menu of plant drugs. In the nineteenth century, these drugs became commodities distributed on international markets, and were used not only as medicines but as substances around which new cultures grew up. The romantics, the pre-Raphaelites, the French decadents were amongst the many literary and artistic subcultures that employed drugs to change consciousness and as elements in a countercultural identity.

The point in raising this historical context is not simply to prove that UNODC is mistaken in dating the birth of youth-oriented drug cultures to the 1960s, but to stress that drugs have been an essential part of social life and culture for hundreds of years, and that they have played many roles beyond the purely problematic one that UNODC continuously seeks to highlight. ${ }^{25}$ Moreover, their use has risen and fallen in cycles throughout the modern period, a stubborn historical fact that poses serious problems for projects aiming ultimately to restrict their uses solely to 'medical and scientific' purposes. ${ }^{26}$ This integral relationship between drugs and modern ways of life represents a type of challenge to which the UN drug control regime shows little sign of rising to meet.

\section{The Report's finding that drug use has been successfully contained amongst adults}

The Report also proposes a hypothesis to account for its observed containment of drug use amongst the young. This 'may actually be less the result of a higher propensity among young people to take drugs than the effect of a lower propensity of adults to transgress laws and social norms' (p.64). Deployed in support of this hypothesis are data showing that the prevalence rates for illicit substance use drop much more rapidly than that for use of licit substances as people age. The existence of the drug control system, with its prohibitive stance in relation to the non-medical use of drugs, is celebrated once again as the limiter of harms: its system of laws and norms is credited with restricting drug use to a youth population that is more reckless in its attitude toward the transgression of laws and norms. Thus, the text suggests that 'the drug control system acts as a powerful brake against the extension of illicit drug use from adolescence to maturity' (p.64). This thesis is difficult to either prove or disprove. Although the data indicate that drugs are primarily used by youth, the data may be a statistical artifice, and misleading: the police tend to focus their interdiction efforts on young people, especially those who dress and speak in 'counter-cultural' ways, or who belong to ethnic minorities. ${ }^{27}$ Drug use data are socially constructed, and their provisional and tentative nature should be kept continually in mind. Moreover, youth may show a greater frankness about their drug use, whereas adults, with more to lose economically and socially, may tend to be more discreet. It is likely that at least some degree of distortion is present in the data as a result of such factors. ${ }^{28}$

Yet even if these data were accurate, there are numerous other alternative cultural and social interpretations. Drugs are often associated with youth culture, and many people simply stop using them when they become engaged in building careers, families and so on. Such a step may be taken not from fear of police repression, 
but as a result of a change in attitude. The essential point here is that UNODC is rather too enthusiastic in assigning phenomena to the effectiveness of the drug control system, when there are often competing explanations carrying just as much force.

\section{UNODC's analysis of factors driving drug use}

Section $C$ is where the discussion concentrates on various factors (other than those mentioned above) that are said to be shaping the evolution of the contemporary drug landscape. The themes presented in this section include:

- Socio-demographic drivers - essentially this reiterates the point that the typical drug user is a young male living in a city'; in fact, these passages describe drug prevalence in demographic terms, and do not attempt to identify causes or 'drivers'.

- Socio-cultural drivers - this refers to the type of cultural factors that UNODC has in the past preferred to evade, though it is far from alone in doing so. As the text remarks, 'some of these phenomena are difficult to measure and quantify' (p.87). Commendably, the Report nevertheless does try to get to grips with the issue, and begins by stating that, 'The most significant sociocultural driving factor for the evolution of the drug problem appears to have been the popularization of a youth culture' (p.87). The text continues: 'In many developing countries, this has taken place alongside an orientation toward a Western way of life, which may, for some, include the temptation to use illicit drugs' (p.87). It also notes that these processes of social and cultural change are characterised by 'a trend toward decreasing social control', with migration and urbanisation tending to attenuate traditional values and 'strong family ties' (p.87). The listed sociocultural drivers also refer to the topic of religion, which is often 'anti-drug' in its ethics and which, according to UNODC, may constitute a form of 'protection' for individuals against the corrosive effects of drugs. The last factor to be mentioned here is the effect on children and adolescents of environmental circumstances such as violence, neglect, abuse, instability, household dysfunction and so on, although the categorisation of such issues as 'sociocultural' in the sense that youth cultures are 'sociocultural', is a problematic item of typology.

- Socio-economic drivers - these passages focus on the linkage of drug use with the availability of disposable income, though it adds the caveat that this factor in isolation has little explanatory power. For example, Swedish citizens have high levels of disposable income yet drug use is relatively low, while the opposite conditions obtain in Afghanistan. Social inequality, disadvantage and unemployment are also strongly linked with drug use. ${ }^{29}$ The drug control system itself is then discussed as a means of drug prevention, and a list of several national examples used in support of the argument that 'drug control interventions' have suppressed drug production, trafficking and use. However, the choice of cases used is very selective, presenting evidence that supports UNODC's arguments while ignoring the numerous cases that do not (and even amongst the cases chosen, the argument is often weak). For example, little awareness is shown of the problem of substance displacement, where users denied access to a given drug will change to an alternative rather than become abstinent. The text acknowledges the reality of such a 'balloon effect', but appears unaware of a key long term characteristic of the illicit market, namely, that as mechanisms of suppression are brought to bear upon these substances, they return in more concentrated, radical and potentially hazardous forms. It 
appears that only when opium smoking was legally suppressed in South East Asia, for example, the (much more dangerous) injecting of heroin occupied its place. ${ }^{30}$

The Report also showcases instances such as the Chinese communist suppression of opium use during the 1950s are mentioned as successes, while they were achieved only at the cost of levels of social repression that would be considered wholly unacceptable by the majority of people in liberal democracies. ${ }^{31}$

A number of 'formal theories' are then briefly discussed, such as those which analyse drug use according to a disease model of epidemics. 'Unforeseeable factors' which change the shape of drug markets are reviewed in summary, and included in this category are the 'unintended consequences' of drug control mentioned above. 'The development of black markets and opportunities they create for organised crime', note the authors, 'have been among the unintended side effects' (p.93). This is an extraordinary statement, which downplays the fundamental role that the drug control regime has in creating the illicit market, and placing this group of commodities outside the regulatory systems that govern and oversee the production, commercial transactions and consumption of other commodities in contemporary societies. The regime has, by virtue of its very existence, composed a space in which governance and oversight do not function, and in which demand is instead met by illicit organisations having no state restrictions placed upon the profit motive. ${ }^{32}$

Predictions for the future of 'the drug problem' Before reaching its concluding paragraphs, the chapter seeks to address the possible developments for 'the drug problem' in the near future. To do so, it draws on the patterns elaborated in the previous sections, and arrives at three sets of potentials, which it terms the likely, the possible, and the unknown. The first of these is based on demographic projections of a global population currently at 7 billion, estimated to be 9.3 billion by 2050 and 10.1 billion by 2100 . It predicts that drug use will remain concentrated amongst youth, while the 'gender gap' (more men than women using drugs) looks likely to reduce as developing countries modernise and gender inequalities diminish. Increasing urbanisation will combine with these factors to lead to expanding use in developing nations, especially in Africa. On the other hand, the growth of an ageing population in the developed world will counteract this trend, with overall levels of prevalence likely to remain stable. The rising numbers of consumers located in developing nations, which will represent an increased proportion of the market, means that profits for organised crime drug trafficking groups will likely decrease. In such circumstances, the Report expects that the trade will make up some 0.5 per cent of global GDP, or even less. By way of comparison, the current figure is approximately 1.5 per cent of global GDP. ${ }^{33}$

Under the heading of 'the possible', the proposed scenario is one in which heroin and cocaine markets decline. Efforts by governments 'should eventually' lead to sustainable crop eradication (p.95). In a statement that echoes the high expectations of the early, heroic years of the drug control regime, the text claims that, "History has also shown Governments that a closely coordinated approach at the international level is required to prevent the balloon effect'. Since the balloon effect is as much a part of the global drug scene as it has ever been, and has never been prevented in the long or even medium term, these claims are dubious. We might compare the UNODC's optimism with the sober assessment of the highly respected commentators Paoli, Greenfield and Reuter, writing in 2009 of the future prospects for cutting illicit opiate supplies: 'In sum, our analysis does not augur well for the international drug control regime. We find little reason to predict success in reducing the world supply of opiates and only limited opportunities to affect national or regional conditions. ${ }^{34}$ The 
caution shown by these authors is informed by a historical background in which the illicit trade has repeatedly adjusted to the strategies of law enforcement, and managed to maintain the flow of its products to a global consumer base. Despite being beyond the law, it remains a dynamic mode of consumer capitalism that has consistently remained ahead of the control regime, and shows little prospect of changing in this regard. More realistically, the Report observes that there are no signs of the cannabis market reducing in dimensions, and acknowledges that use of ATS and other synthetic drugs looks set to grow.

In the third set of potentials, discussed under the moniker of 'the unknown', UNODC recognises that, 'History has shown...that unforeseen events can play a bigger role in shaping the drug problem than many of the other factors' (p.96). The most refreshing aspect of this section is its candid stance toward the play of events, although it uses up most of this space warning of dire consequences 'in the unlikely event of a fundamentally changed drug control system' (p.96). Here, the argument is that the reduced prices that would follow from a legalised market may well lead to increases in consumption, particularly for heroin and cocaine.

Overall, however, the predictive value of many of these points is very limited. The data upon which they rely is almost certainly inadequate, even as a basis for making large generalisations about the present, let alone the future. Rather than depending on a solid foundation of data as they claim, they are instead built upon assumptions about a future which largely disregards the influence of cultural movements and shifts of perception - those 'unpredictable fashion-type evolutions' (p.93) that are so difficult to quantify and yet so central to the symbolic meanings that drugs transmit to their users and, usually in different ways, to those concerned in ordering and governing social and cultural life.

\section{Conclusions}

As usual, there is much that is valuable in the World Drug Report 2012. While there remain major issues with data capture, methodology and consequent interpretation, the Report provides broad ranges for its estimates. In addition, its detailed collation and trend analysis is supplemented by a thematic chapter which, among other things, initiates a discussion of cultural and historical themes that UNODC sees as informing and underlying the contemporary 'world drug problem'.

IDPC argues, however, that chapter two is too concerned to defend the achievements of the drug control regime to really take up the opportunity offered by its discussion. Such a vociferous defence, as echoed in the UNODC Executive Director's Preface, leave us in no doubt that UNODC perceives the drug control system as being under threat of unravelling. (Ironically, an enhanced degree of flexibility on behalf of the system may be the best way to retain it - a situation of 'bend or break'. ${ }^{35}$ ) Yet the defence of the conventions and the system that they underpin is inscribed in the interpretation of the data in the main body of the Report.

The presence of the containment narrative, which defends the alleged achievements of the drug control system, is prominent. Nonetheless, it is highly likely that there are hidden populations of drug consumers, as UNODC itself acknowledges, and that these, in combination with the failure of several member states with large populations to return Annual Report Questionnaires, render the 'real' size of the illicit drug using population an unknown quantity, and a matter for conjecture. Moreover, the market situation is perpetually mobile; as the authors observe, '... while the troubled waters of the world's illicit drug markets may appear to be stagnant, shifts and currents in their flows and currents can be observed beneath the surface' (p.1). Under 


\section{Idpc}

such circumstances, the containment thesis inevitably looks fragile. UNODC may be unwise, therefore, to pin its strategy on such shifting sands. An alternative would be for it to continue down a path on which it has already taken a few tentative steps, and to act as a 'critical friend' to the broader system. In this vein, and aware of the methodological challenges that it would generate, the centenary of the international control framework is perhaps also an appropriate time to devote more attention to measuring the costs and 'unintended consequences' of the system that, much like the real state of shifting markets, currently lie hidden and below the data presented in the Report. ${ }^{36}$

\section{Acknowledgments}

Thanks go to the IDPC Secretariat, IDPC members, and to others who in various ways contributed to the content of this report. Particular thanks go to Ajay Kumar Solanki, Ajeng Larasati, Kosum Omphornuwat, Maheswar Satpathy, Sankar Arumuham and Umananda Chakpram for highlighting the problems within UNODC's extrapolation methodology. The usual caveat applies with any errors of fact or misinterpretation being the responsibility of the lead authors.

The International Drug Policy Consortium is a global network of non-government organisations and professional networks that specialise in issues related to illegal drug production and use. The Consortium aims to promote objective and open debate on the effectiveness, direction and content of drug policies at national and international level, and supports evidence-based policies that are effective in reducing drug-related harm. It produces occasional briefing papers, disseminates the reports of its member organisations about particular drug-related matters, and offers expert consultancy services to policy makers and officials around the world. 


\section{Endnotes}

1 Comments of the President of the General Assembly, Nassir Abdulaziz Al-Nasser. The General Assembly launch can be viewed at: Thematic Debate on 'Drugs and Crime as a Threat to Development' - General Assembly: http://webtv.un.org/search/part-i-thematicdebate-on-drugs-and-crime-as-a-threat-to-development-general-assembly/1708151144001?term=Wor Id_Drug_Report

2 Opening Speech at the Plenary, $55^{\text {th }}$ Session of the Commission on Narcotic Drugs 2012, http://www.unodc.org/unodc/en/speeches/speech55sessioncommission-on-narcotic-drugs.html

3 United Nations Office on Drugs and Crime (2012), World Drug Report 2012, Methodology, p. 6, http://www.unodc.org/unodc/en/data-and-analysis/WDR-2012.html

4 ARQs that were more than 50 per cent completed were classified as having been 'substantially filled in'; less than 50 per cent completion is classified as having been 'partially' filled in. See: United Nations Office on Drugs and Crime (2012), World Drug Report 2012, Methodology, p. 1, http://www.unodc.org/unodc/en/data-andanalysis/WDR-2012.html

5 Opiates are derived from papaver somniferum, the opium poppy; they include opium, morphine, codeine and heroin. The term 'opioids' applies to any substances which binds to the opioid receptors in the nervous system, but is usually restricted to synthetic substances having opiate-like properties: they include methadone, fentanyl, tramadol etc.

6 International Drug Policy Consortium (2011), IDPC Response to the UNODC World Drug Report, p. 16, http:// idpc.net/publications/2011/09/idpc-response-to-unodc-2011-world-drug-report

7 United Nations Office on Drugs and Crime (2012), 2012 World Drug Report, Methodology p. 1. http://www. unodc.org/documents/data-and-analysis/WDR2012/ Methodology.pdf

8 International Drug Policy Consortium (2011), IDPC Response to the UNODC World Drug Report, p. 8, http:// idpc.net/publications/2011/09/idpc-response-to-unodc-2011-world-drug-report

9 These include data sets produced by Afghan organisations conducting fieldwork within the country.

10 United Nations Office on Drugs and Crime, Press Release, 'Coca crop cultivation "falls significantly" in Bolivia according to 2011 coca monitoring survey' http://www. unodc.org/unodc/en/frontpage/2012/September/coca-crop-cultivation-falls-significantly-in-bolivia-according-to-2011-coca-monitoring-survey.html? ref=fs3 See report in Spanish at: http://www.unodc.org/docu-
ments/crop-monitoring/Bolivia/Bolivia_coca_survey_spanish_2012_web.pdf

11 Ledebur, K. \& Youngers, C.A. (21 September 2012), US slams Bolivian drug control efforts lauded by UN, http:// www.wola.org/commentary/washington_in_wonderland

12 For a discussion on the US position, see: Ledebur, K. \& Youngers, C.A. (21 September 2012), US slams Bolivian drug control efforts lauded by UN, http://www.wola. org/commentary/washington_in_wonderland

13 See, for example: Washington Office on Latin America (31 July 2012), UN and US estimates for cocaine production contradict each other, http://www.wola.org/ commentary/un_and_us_estimates_for_cocaine_ production_contradict_each_other

14 The average gross income for a cannabis growing household was about $\$ 9,000$ in 2010 , compared to $\$ 4,900$ for poppy. United Nations Office on Drugs and Crime (2012), World Drug Report 2012, p. 45, http:// www.unodc.org/unodc/en/data-and-analysis/WDR2012.html

15 See, for example United Nations Office on Drugs and Crime (2006), World Drug Report 2006, Volume 1: Analysis, pp. 172-186, http://www.unodc.org/unodc/ en/data-and-analysis/WDR-2006.html

16 Hallam, C. \& Bewley-Taylor, D. (2010) 'Mapping the world drug problem: Science and Politics in the United Nations drug control system', The International Journal of Drug Policy, 21(1): 1-3

17 Hallam, C. \& Bewley-Taylor, D. (2010), Drug use: Knowledge, culture \& context (Beckley Foundation), http:// www.beckleyfoundation.org/pdf/BeckleyBriefing21.pdf

18 Costa, A.M. (2008) 'Making drug control 'fit for purpose': Building on the UNGASS decade' (Vienna: United Nations Office on Drugs and Crime), http://www.unodc. org/documents/commissions/CND-Session51/CNDUNGASS-CRPs/ECN72008CRP17.pdf

19 Schivelbusch, W. (1993,) Tastes of paradise: A social history of spices, stimulants and intoxicants (New York: Vintage)

20 Bancroft, A. (2009), Drugs, intoxication \& society (Cambridge: Polity Press)

21 Levine, H.G. (1985), 'The birth of American alcohol control: Prohibition, the power elite and the problem of Lawlessness', Contemporary Drug Problems, Spring: 63-115, http://dragon.soc.qc.cuny.edu/Staff/levine/ The-Birth-of-American-Alcohol-Control.pdf

22 International Drug Policy Consortium (2008), The World Drug Report 2008: A response from the International Drug Policy Consortium http://idpc.net/publications/2008/09/idpc-response-to-unodcs-world- 
drug-report

23 For historical analyses of the 1960s, see Marwick, A. (1998), The sixties: Cultural transformation in Britain, France, Italy and the United States, 1958-74 (Oxford University Press); Donnelly, M. (2005), Sixties Britain: Culture, society and politics (Harlow: Longman)

24 Courtwright, D.T. (2001), Forces of habit: Drugs and the making of the modern world (Cambridge: Harvard University Press)

25 Klein, A. (2008), Drugs and the world (London: Reaktion Books)

26 Schneider, E. (2008), Smack: Heroin and the American city (University of Pennsylvania Press)

27 Stevens, A. (2011), Drugs, crime and public health: The political economy of drug policy (Abingdon: Routledge)

28 Kalunta-Crumpton, A. (1999), Race and drug trials: The social construction of guilt and innocence (London: Ashgate); Muncie, J. (2009), Youth and crime: Third edition (London: Sage), especially Chapter 1

29 International Drug Policy Consortium (2012) Drug Policy Guide, $2^{\text {nd }}$ Edition, http://idpc.net/publications/2012/03/idpc-drug-policy-guide-2nd-edition

30 Westermeyer, J. (1976), 'The pro-heroin effects of anti-opium laws in Asia', Archives of General Psychiatry, 3: 1135-1139 http://adlrf.org.au/wp-content/uploads/2012/02/Westermeyer-1976-The-Pro-Heroin-
Effects-of-Anti-Opium-Laws-in-Asia.pdf

31 Dikotter, F., Laamann, L. \& Xun, Z. (2004), Narcotic culture: A history of drugs in China (London: Hurst and Co.)

32 Transform Drug Policy Foundation (2009), After the war on drugs: Blueprint for regulation, http://www.tdpf.org. uk/blueprint\%20download.htm

33 United Nations Office on Drugs and Crime (2011), Estimating illicit financial flows resulting from drug trafficking and other transnational organized crimes, http:// www.unodc.org/documents/data-and-analysis/Studies/Illicit_financial_flows_2011_web.pdf

34 Paoli, L., Greenfield, V.A. \& Reuter, P. (2009), The world heroin market: Can supply be cut? (Oxford University Press)

35 Bewley-Taylor, D, (2012), International drug control: Consensus fractured (Cambridge University Press), pp. 279-336

36 For more, see: Transform Drug Policy Foundation (2012), The Alternative world drug report: Counting the costs of the war on drugs, http://evolvecms.webfreelancersuk.co.uk/sites/default/files/AWDR.pdf; Bangkok Post (18 September 2012), Are our drug policies really working?, http://idpc.net/alerts/2012/09/areour-drug-policies-really-working

\section{OPEN SOCIETY}

International Drug Policy Consortium

Fifth floor, 124-128 City Road, London

EC1V 2NJ, United Kingdom

telephone: +44 (0)20 73242975

email: contact@idpc.net

website: www.idpc.net

Copyright (C) 2012 International Drug Policy Consortium All rights reserved 